\title{
Materiales arqueológicos recuperados a un costado de la Catedral Metropolitana de la Ciudad de México
}

\author{
Edgar Nebot García \\ Escuela Nacional de Antropología e Historia (México) \\ ednebot@hotmail.com
}

Recibido: 6 de abril de 2010

Aceptado: 17 de mayo de 2010

\section{RESUMEN}

Las intervenciones de rescate arqueológico en la Ciudad de México han permitido a los investigadores ir reconstruyendo el panorama histórico de la primera urbe hispana en América desde tiempos anteriores a la presencia europea. Este artículo da a conocer los hallazgos realizados durante las excavaciones civiles en una de las jardineras situadas en el costado poniente de la Catedral Metropolitana: restos arquitectónicos posiblemente relacionados con el conjunto urbano circundante al primer templo católico de la ciudad colonial; estratigrafía artificial local y basura del siglo XVI que formaba parte del relleno del subsuelo, constituida principalmente por alfarería prehispánica y cerámica colonial de manufactura nacional e importada; y restos óseos de fauna que formaron parte del consumo diario de los habitantes en los que se pudieron detectar distintas alteraciones antrópicas producidas durante la elaboración de alimentos.

Palabras clave: México, catedral metropolitana, cerámica azteca, cerámica colonial, restos óseos.

\section{Archaeological Remains Recovered Beside the Metropolitan Cathedral of Mexico City}

\begin{abstract}
The interventions of archaeological recovery in Mexico City have allowed researchers to rebuild the historical outlook of the first Hispanic metropolis in America, even ages before the European presence. This article shows the discoveries made during the excavations of civil work in one of the jardinières located in the west side of the Metropolitan Cathedral, which came up interesting because of the finding of architectonic remains, perhaps related to the urban complex surrounding the pristine catholic temple of the colonial city, and also because of the local artificial stratigraphy, along with the rubbish deposits of the $16^{\text {th }}$ century which were a part of the underground filling, and mainly consisted of prehispanic pottery and colonial ceramic of both national and imported manufacture, with the addition of diverse animal bone remains that were part of the residents daily consumption, and in which varied anthropic alterations formed during food processing were detected.
\end{abstract}

Key words: Mexico, Metropolitan Cathedral, Aztec pottery, colonial pottery, bone remains.

Sumario: 1. Introducción. 2. Estratigrafía y hallazgos arquitectónicos. 3. La cerámica del Pozo no ${ }^{\circ}$. 4. Acerca de los azulejos recuperados. 5. Restos faunísticos. 6. Reflexiones concernientes a la evidencia material hallada en el Pozo $n^{\circ}$ 1. 7. Referencias bibliográficas.

\section{Introducción}

La arqueología del centro de la Ciudad de México ha representado siempre un interesante rompecabezas que, además de permitir la reconstrucción de la historia pre- 


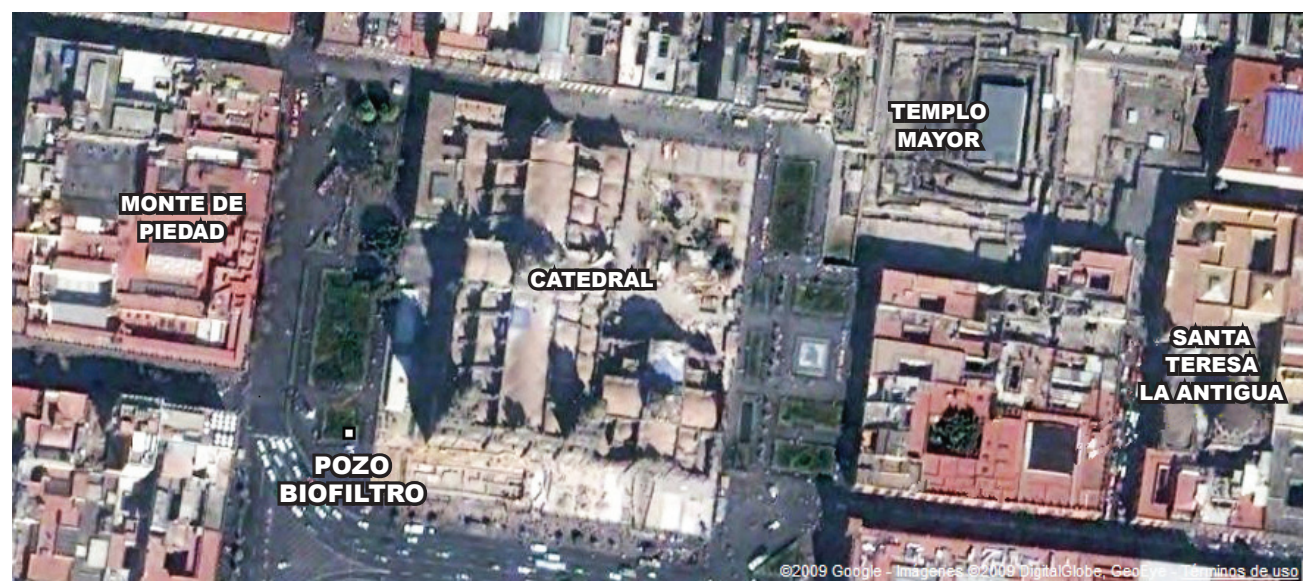

Figura 1: Localización del Pozo No. 1 junto a la Catedral Metropolitana de la Ciudad de México.

(Tomado y modificado de Google Earth, 2010).

hispánica, es también de vital importancia para el entendimiento socioeconómico de la población virreinal citadina, desde el momento del contacto hispano hasta muy a principios del siglo XIX. Con motivo de la instalación de un dispositivo conocido con el nombre de biofiltro, en el extremo poniente de la Catedral Metropolitana por parte de una compañía civil, el martes 23 de diciembre de 2008 y bajo la supervisión del Programa de Arqueología Urbana (PAU) del Instituto Nacional de Antropología e Historia, comenzó una excavación en la jardinera que se ubica en la esquina formada por las calles Monte de Piedad y Cinco de Mayo, la cual tuvo una extensión de $4 \mathrm{~m}$ por $4 \mathrm{~m}$, con una profundidad máxima de 2,30 $\mathrm{m}$ y que se denominó Pozo Número 1 (Figura 1). Gracias a esa labor de rescate se lograron recuperar algunos vestigios tanto de tipo arquitectónico como artefactos residuales que incluyen principalmente cerámica y restos óseos (ver Nebot 2009).

La idea de este artículo es aportar más datos al conocimiento arqueológico de la etapa colonial de la gran urbe, con especial énfasis en las cercanías de la Catedral Metropolitana y más aún en el área en donde se encontraba levantado originalmente el primer templo católico de toda América (Figura 2). Sin lugar a dudas la referencia histórica más importante de este área es la erección de lo que fuera la primera catedral de la Ciudad de México y fue principalmente Manuel Toussaint quien se ocupó de investigar el origen y localización del antiguo recinto religioso. De acuerdo con la valiosísima información aportada por el sabio mexicano, la primitiva iglesia fue construida entre 1524 y 1532 por orden de Hernán Cortés, siendo el arquitecto encargado de la obra el maese Martín de Sepúlveda y fue ocupada por la orden franciscana española (Toussaint 1992: 17 y 18). La catedral, de acuerdo con la labor de investigación documental de Don Joaquín García Icazbalceta, se encontraba en la esquina noroeste de lo que actualmente es el atrio de la «nueva» catedral y, según la descripción aportada por el mismo Toussaint, se trataba de un edificio de estilo mudéjar y de planta basilical, con tres naves separadas por dos danzas de pilares ochavados correspondientes al orden toscano, cubierta por un techo central de dos aguas y con 
otros laterales fabricados con vigas planas que permitían abrir ventanas hacia la nave mayor (Toussaint 1992: 18).

Hacia la segunda mitad del siglo y debido al ruinoso estado del edificio, bajo el mandato del entonces arzobispo y virrey Don Pedro Moya de Contreras, se ordenó una reparación general de la iglesia en la que figuraron los artífices más importantes que se encontraban en México en ese tiempo, extendiéndose las actividades de mantenimiento a lo largo del siglo XVII hasta que, en 1626, se derribó la primitiva catedral, tal vez con el pretexto de acelerar la construcción del nuevo edificio que la sustituiría; situación que no se presentó de la manera en que estaba pensada ya que la obra marchó a paso más lento de lo previsto (Toussaint 1992: 18 y 19).

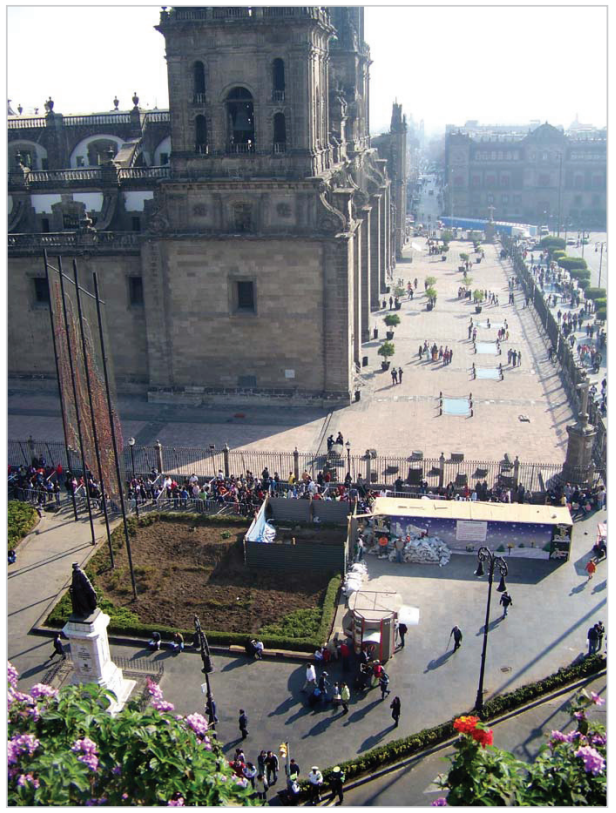

Figura 2: Vista aérea del Pozo No. 1 desde el poniente con la Catedral Metropolitana y el Palacio Nacional al fondo.

Realmente se ha escrito y publicado poco e incluso hay todavía material inédito sobre las exploraciones aledañas al extremo occidental del imponente monumento religioso. Aunque en lo concerniente a las excavaciones algunas intervenciones han sido tan pequeñas como lo fue nuestro caso, consideramos que es necesario dar a conocer sus resultados para comunicar a los interesados en el tema la situación cronológica, constructiva y socioeconómica de la población correspondiente a las dos primeras centurias de la ocupación española en la localidad.

Las áreas de exploración arqueológica más cercanas al pozo del biofiltro y que se encuentran publicadas, son las que Antonio García Cubas llevó a cabo en el atrio sur de la última catedral en 1881, en las que se encontraron cabezas de ofidios y otras rocas labradas que pudieron haber sido las bases correspondientes a la primera iglesia metropolitana, aunque no se aportan mayores detalles del lugar preciso de los descubrimientos y de las condiciones de los mismos (Cubas citado en Peña 1988: 417). Posteriormente, no fue hasta 1982 cuando la Dirección de Monumentos Histó- 
ricos dependiente del INAH realizó una serie de excavaciones en el mismo extremo meridional del atrio, hallándose restos arquitectónicos de lo que fuera la primera catedral de la urbe mexicana correspondientes a lo que, según los testimonios escritos existentes de la descripción de la iglesia, serían las capillas laterales y la curia. En cuanto a los altares, de uno de ellos todavía se conservaban los escalones de acceso a la parte superior del mismo, decorados con recubrimientos de azulejos polícromos, así como también parte de la mesa en donde se realizaban los oficios; adicionalmente se exhumaron los muros que limitaban la capilla, una habitación en la parte posterior del altar y, junto a la capilla, el segundo altar del que únicamente se conservaron las huellas del desplante y parte del solado construido con ladrillo y azulejo intercalado, existiendo en su costado derecho un acceso a un cuarto trasero en el que todavía podían observarse las huellas dejadas por los azulejos (De la Peña 1988: 417 y 420).

\section{Estratigrafía y hallazgos arquitectónicos}

Entrando de lleno en la descripción arqueológica de nuestro Pozo ${ }^{\circ} 1$, además de una alteración moderna no significativa que se detectó en el extremo poniente, se registraron un total de cuatro estratos, de los cuales la capa IV es el depósito que contiene los restos arqueológicos, tanto arquitectónicos como artefactos cerámicos, líticos, de vidrio y los desechos óseos paleozoológicos, así como también una interesante división interna en horizontes culturales muy característicos de las formaciones antrópicas de la Ciudad de México.

El estrato número IV es una capa formada por una arcilla plástica de color café oscuro/grisáceo con una textura semigranulosa al tacto, bien consolidada y de fractura en bloque. Los restos arqueológicos se encontraban distribuidos a lo largo y ancho de tres horizontes que se diferencian poco del tipo de material arcilloso, pero muestran variaciones en su contenido arqueológico. El «Horizonte IVa», entre los $40 \mathrm{~cm}$. hasta el $1.24 \mathrm{~m}$. de profundidad, se caracteriza por tener materiales arqueológicos predominantemente de época colonial, mezclados con unos cuantos residuos de tiempos muy recientes. El «Horizonte IVb» se ubica entre los $99 \mathrm{~cm} . / 1.24 \mathrm{~m}$. -ya que existe una inclinación sinuosa de sur a norte teniendo su punto más alto en la parte superior del Elemento arquitectónico No. 2-y el $1.72 \mathrm{~m}$. de profundidad; se trata de la misma arcilla registrada en la franja superior, pero se observan diferencias sutiles principalmente en una mayor plasticidad, oscurecimiento y nivel de humedad del material; se aprecia un significativo aumento de los materiales arqueológicos coloniales y la aparición de alfarería prehispánica revuelta con la vajilla mexicana, europea y oriental del periodo virreinal. El «Horizonte IVc», desde el $1.72 \mathrm{~m}$. hasta los $2.30 \mathrm{~m}$. de profundidad, tiene las mismas características litológicas y visuales del material arcilloso del Horizonte IV, pero con un rasgo muy específico y es la presencia dominante de material de contacto y de época mexica sobre la evidencia colonial.

Con respecto a la arquitectura del yacimiento, en el Pozo $\mathrm{n}^{\circ} 1$ se exhumaron dos evidencias que, debido a su liberación parcial por el reducido tamaño del área de excavación, no se pudo conocer la dimensión real de las construcciones, así como tampoco su relación entre ambas y con otros restos de la misma índole; por dicho 
motivo se designaron como «Elementos arquitectónicos 1 y 2» por no saber con toda certeza cuál era su forma y función específica. El Elemento arquitectónico No. 1 se descubrió en la fracción noreste del Pozo 1, a una profundidad de $80 \mathrm{~cm}$ y con su piso de desplante a una media de 1,61 m de profundidad; se trata de los restos de lo que parece haber sido un pilar o una estructura cuadrangular parcialmente destruida (Figura 3). Estaba inmersa dentro de la capa IV y la lentícula arcillo-arenosa es la que marca aproximadamente el área de desplante de este semicubo de bloques trabajados, abarcando de abajo hacia arriba el Horizonte «b» -época en la que presumiblemente fue levantado el conjunto- y parte del Horizonte «a».

El probable pilar fue construido a partir de bloques fabricados con roca grisácea de grano fino y estructura sólida correspondiente a una cantera regional conocida con el nombre de Chiluca, los cuales tienen superficies planas debido a que fueron labrados de tres maneras: en bloque rectangular, en forma trapezoidal y en forma escalonada, todos ellos unidos entre sí mediante una mezcla arcillo/arenosa de color café grisáceo con algunas vetas de color gris. Entre las juntas se observó también la colocación de ladrillo delgado, así como partículas calcáreas amarillentas. Se conservan aún ocho bloques que integran el cuerpo de la estructura y, a los pies del semicubo, hacia la cara norte del mismo macizo, se hallaron un par de rocas de tipo basáltico paralelas entre sí y también trabajadas de forma rectangular aunque de contornos un tanto irregulares, que se encuentran a una profundidad media de $1,49 \mathrm{~m}$ y que podrían haber sido parte de la base del pilar. La altura total del Elemento arquitectónico No. 1 es de $80 \mathrm{~cm}$ y el largo es de $76 \mathrm{~cm}$-de este a oeste- con $48 \mathrm{~cm}$ de ancho máximo -costado oriente- por $42 \mathrm{~cm}$ de ancho mínimo -costado poniente-

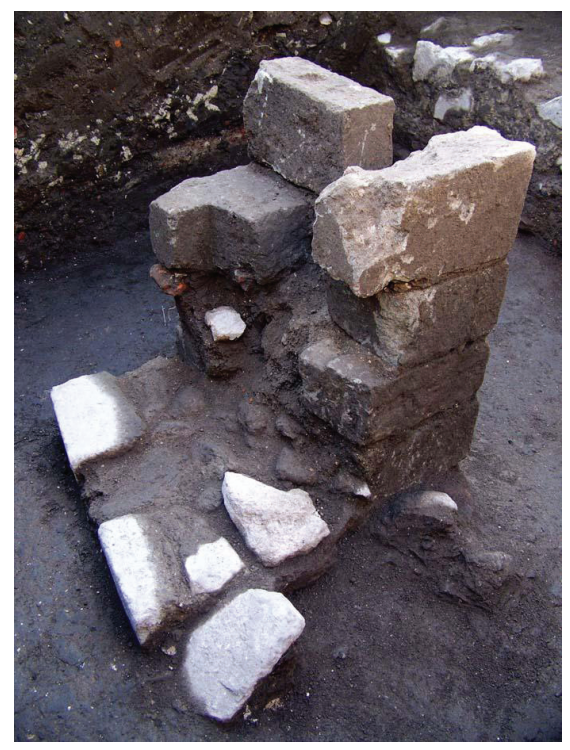

Figura 3: Elemento arquitectónico No. 1.

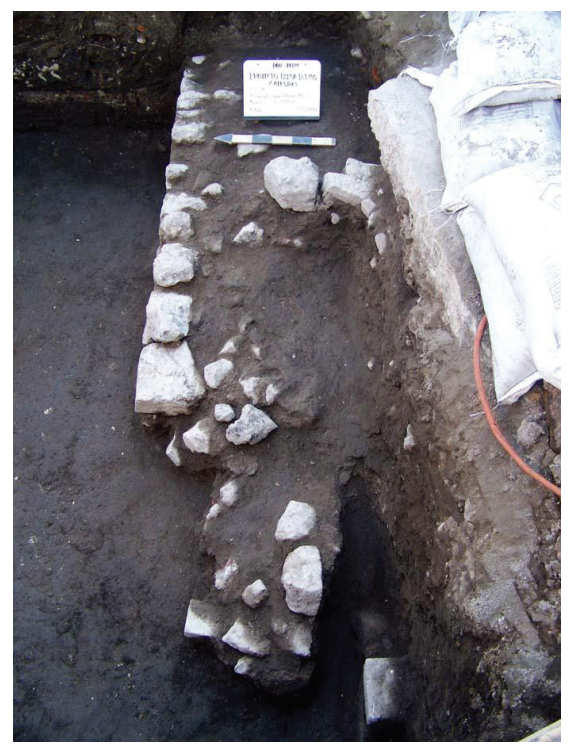

Figura 4: Elemento arquitectónico No. 2. 
El Elemento arquitectónico No. 2 es una construcción exhumada parcialmente que se encuentra en el extremo sur del Pozo 1 y continúa hacia el interior, tanto de la pared meridional como de la oriental (Figura 4). Se trata de una especie de basamento de una altura media de $76 \mathrm{~cm}$, con un núcleo formado por una gran masa de arcilla del mismo tipo del estrato número IV y que está reforzado por una buena cantidad de trozos de roca de origen ígneo que en su mayoría no están trabajadas -las piedras que se lograron reconocer son de tipo basáltico, tezontle y piedra rosada que aparentemente podría ser andesita-, de tamaño mediano y pequeño que dan cuerpo y cohesión al elemento arquitectónico, mientras que el costado visible de la estructura -cara norte- está constituido por una hilada de roca ígnea -tipo basáltica y tezontle rojo-que mide 2,28 m de largo por $26 \mathrm{~cm}$ de ancho (tomando en consideración solamente un promedio de las rocas trabajadas dispuestas en la orilla superior y no de todo el basamento). La forma de los bloques tiende a ser irregular, aunque existen casos en los que la piedra fue rebajada por una o dos de sus caras para formar superficies planas; $\mathrm{y}$ en lo que concierne a su base o punto más bajo de desplante, se acomodaron en hilera una serie de piedras de tamaño más reducido que las trabajadas aunque todas eran de la misma materia prima.

La correspondencia estratigráfica de este monumento pertenece a los horizontes «b» y «c» de la Capa IV; de hecho, la cima de esta construcción es la que marca el contacto del Horizonte «a» con el «b» y en cuanto a sus niveles de desplante tenemos una medida estándar que se corresponde aproximadamente con la profundidad en la que se halló el desplante del Elemento arquitectónico No. 1, por lo que de acuerdo con la información estratigráfica de materiales constructivos y material cerámico asociado $^{1}$ son elementos constructivos contemporáneos.

Como nota final, debemos señalar la presencia de un cúmulo de aplanado que se encontraba localizado en el espacio comprendido entre los elementos arquitectónicos 1 y 2 , unido justo en el perfil oriental del Pozo 1 . Se trata de un amontonamiento de cientos de placas rectangulares fracturadas de diversos tamaños provenientes de lo que parecen ser restos del firme de alguna pared o piso colonial, muy bien aplanadas, y algunas de ellas todavía con restos de pigmento rojo mate en una de sus superficies. El núcleo de dicho cúmulo está integrado mayoritariamente por arcilla que se mezcló para darle cohesión junto con una gran cantidad de roca ígnea, principalmente tezontle rojo de dimensiones variables, así como también algunos fragmentos de ladrillo.

\section{La cerámica del Pozo $n^{0} 1$}

Aunque escasa, la alfarería recuperada en el Pozo 1 resultó ser muy rica en diversidad de tipos cerámicos, principalmente de manufactura virreinal, lo que nos habla de una ocupación principalmente de época colonial, por lo menos en el periodo representado por la franja superior de la Capa IV. Evidentemente la cerámica nos está indicando

\footnotetext{
1 Dentro de los núcleos de ambos elementos arquitectónicos y mezclados con tiestos prehispánicos, se hallaron algunos fragmentos de terracota colonial y de manufactura local tales como la cerámica roja bruñida de contacto, el vidriado café y el verde, cerámica roja alisada decorada con incrustación, además de los tipos de mayólica importada conocidos con los nombres de «Romita Liso» y «Liguria Azul sobre Azul».
} 
que las dos construcciones datan del periodo colonial y por ello los tipos dominantes más frecuentes en la tabla de porcentajes pertenecen a dicha época que, como es de esperarse, son en su mayoría vasijas de uso cotidiano para la cocción y contención de alimentos ${ }^{2}$.

Comenzando por la cerámica prehispánica, la clasificación de los fragmentos obtenidos de la excavación se basa principalmente en los trabajos de Noguera (1975), Vega (1975) y González (1988), quienes estudiaron en profundidad la alfarería mexica tanto a nivel clasificatorio como cronológico y en donde también se puede consultar la descripción de las formas de los recipientes que básicamente se clasifican, entre otros, en: platos, cajetes, vasos, ánforas, ollas y apaxtles. Domina en la muestra la terracota anaranjada en sus variantes alisada y pulida con o sin decoración; para el caso del naranja alisado se decora con la técnica conocida comúnmente como aplicación «a brochazos» o con manchas de cocción diferencial, y algunas otras no identificadas, con tratamientos superficiales que abarcan la monocromía mate o la aplicación de un baño de engobe lustroso de apariencia metálica, así como la ejecución de motivos incisos con líneas bastante remarcadas, aunque de delineado no muy cuidado, y que parecen formar diseños geométricos compuestos por curvas y líneas también sinuosas pero quebradas.

Se encontraron también tiestos del habitual tipo Azteca III en los que se delinearon líneas paralelas de color negro en el interior de los recipientes, y también contamos con algunas muestras de Azteca IV, estando presentes los diseños en series de bandas paralelas y horizontales de color negro difuminado; tenemos así mismo series de bandas paralelas concéntricas en la cara interna de las vasijas, desde el borde hasta el cuerpo, que pueden presentarse en grupos aislados de tres o más. Un molcajete de soportes rectangulares tiene como decoración en el cuerpo un diseño floral flanqueado por una hilera de más de 10 líneas paralelas e inclinadas (Figura 5).

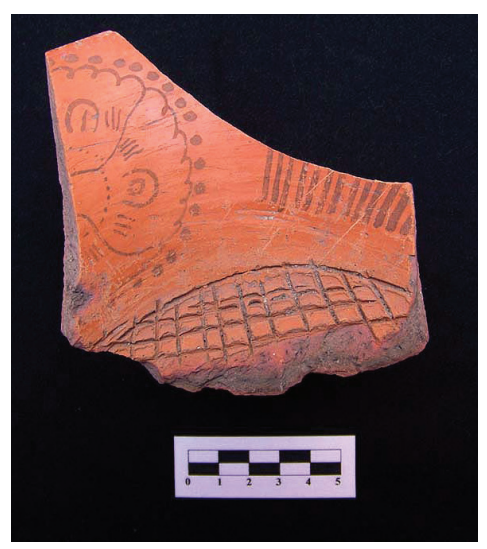

Figura 5: Cerámica mexica decorada correspondiente al tipo Azteca IV.

2 Para una mayor información acerca de los tipos de vasijas, acabados de superficie, técnicas de cocción y tipo de arcilla, entre otros datos técnicos es recomendable consultar el informe respectivo (Nebot 2009: 74-138). 
En la muestra está presente la cerámica café mexica con distintas variedades de tratamiento superficial, las cuales son el monócromo pulido, otro al que se le aplicó un baño de engobe trabajado por medio de la técnica «a palillos», y el denominado Café Naranja, cuya superficie externa tiene un baño de engobe anaranjado que, debido a la cocción, se torna café oscuro en forma de difuminamiento no zonal de apariencia mate; otros ejemplos se hallaron en poca cantidad, como el Chalco Monócromo y el Bícromo; este último exhibe motivos difusos pintados en negro de carácter geométrico que comprenden líneas horizontales paralelas que corren a lo largo de la circunferencia de la pieza y, dentro de algunas de ellas, se perciben semicurvas que forman a modo de olas continuas. Los fragmentos de la tradición roja pulida y bruñida son los ejemplos más abundantes en el Pozo $n^{\circ} 1$, tanto de manufactura prehispánica como de la época del contacto; caso sobresaliente es el Rojo Pulido con decoración Café Negruzca y que se caracteriza por la delineación de elementos decorativos de amplio repertorio: bandas cafés semibrillantes en los bordes y labios exteriores, espirales, líneas serpenteantes, círculos sencillos o con salientes cónicos, rizos, diseños florales compuestos por círculos, o lo que parece ser la zona central de la flor y motivos fungiformes con líneas internas que parecen ser las hojas y grupos de hasta seis finas líneas, largas y paralelas; todo ello en el cuerpo de las distintas vasijas. Y sobre la barbotina roja de otros tipos se delinearon también diseños en color blanco, encontrándose cajetes en los que la decoración se sitúa en la cara externa; se trata de círculos concéntricos o series de líneas paralelas sobre la base plana de la vasija, así como también otros diseños que comprenden líneas curvas, líneas serpenteantes y manchas realizadas con el mismo pigmento que se dibujan sobre el engobe rojo brillante exterior; en otros casos se observa en la cara interna, sobre el cuerpo, una espiral grande.

Por último, forma también parte de la colección del rescate la tradición Cholulteca, representada por algunos fragmentos de platos y cajetes decorados, pero desafortunadamente los motivos centrales están muy erosionados y no pueden ser reconstruidos. Aparte de los colores del fondo y las bandas rojas que circundan el cuerpo, se aprecian solamente motivos delineados en café sobre la cara interna de las vasijas en forma escalonada en hileras seguidas unas con otras y debajo de este panel se observa filas de motas de color rojo apagado (Figura 6), mientras que el borde pequeño de un plato exhibe en su cara exterior un rizo en color rojo.

La alfarería colonial, nacional y extranjera, exhumada en el Pozo $n^{\circ} 1$ se clasificó según el esquema tipológico tradicional expuesto por autores como Goggin (1968 y 1970), López (1976 y 1982) y Lister y Lister (1982), bajo las categorías de cerámica vidriada, mayólica, grupos Barniz-Plúmbeo y Estaño-Plúmbeo, entre otros. En una excavación efectuada en el Centro Histórico el material de terracota obtenido resulta siempre ser muy interesante tanto en cantidad como en variedad, siendo la mayor parte de las veces la cerámica vidriada, utilizada para la cocción y contención de alimentos, la que se encuentra con mayor cantidad en los contextos urbanos. Por lo tanto la mayor parte de los restos del grupo Barniz Plúmbeo de la muestra incluyen los tipos Vidriado Café, Verde, Anaranjado y Negro, con distintas formas tales como cazuelas, cántaros grandes y pequeños, jarros, platos, bacines, jarras, macetas y candeleros, incluyendo en una variante aparte las oliveras. 


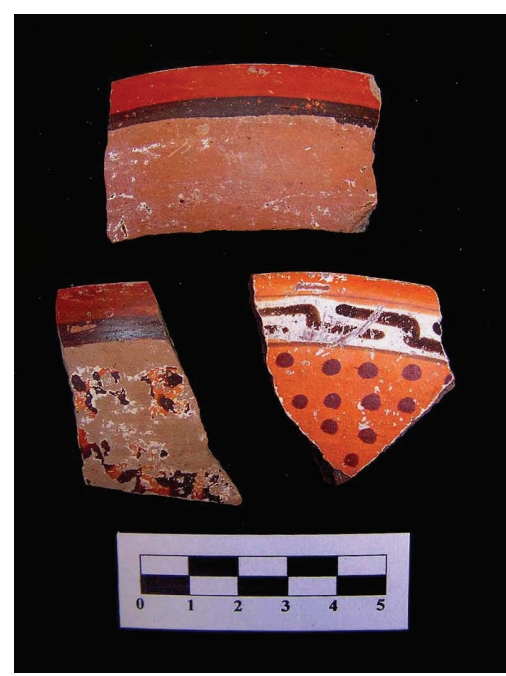

Figura 6: Tiestos del tipo Cholulteca.

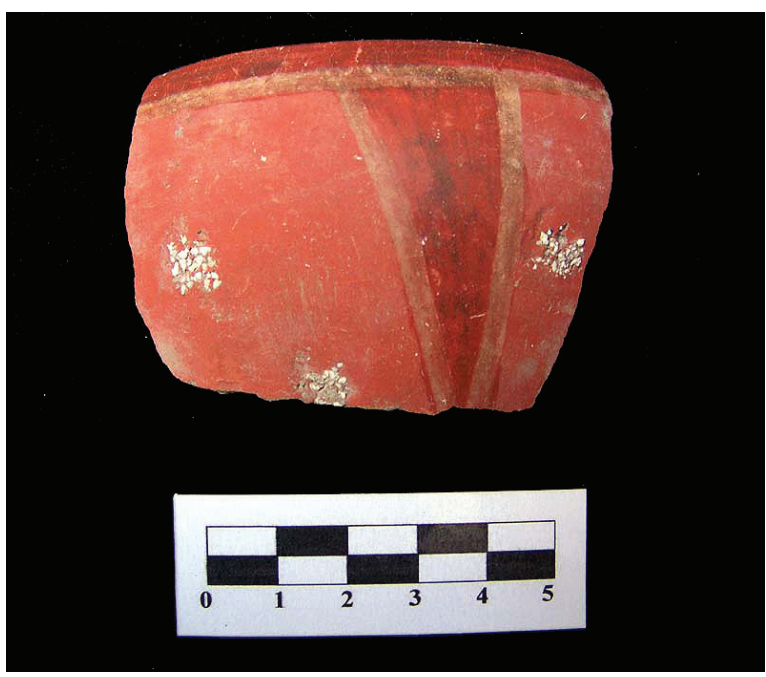

Figura 7: Alfarería roja alisada de principios del periodo virreinal conocida por su decoración incrustada.

Se recuperaron además una buena cantidad de restos de alfarería alisada y pulida del mismo periodo, y contamos con ollas y cuencos decorados con incrustación, en su parte exterior, de pequeños granos de lo que parecen ser cuarzos o feldespatos, e incluso diminutos fragmentos de porcelana (Figura 7). Se encontraron también ejemplos de cerámica anaranjada y roja con distintos tratamientos superficiales, tales como la variante con barbotina cafetosa, o simplemente café cremoso del tipo conocido como «Bizcocho»; y hay un ejemplar con decoración sellada a base de motivos fitomorfos; precisamente la tradición roja es muy abundante y entre los fragmentos se observan el Rojo bruñido de contacto, existiendo un interesante ejemplar: una jarra sobre la que se delineó una rama de estilo muy castellano. Se hallaron también muestras de la tradición decorada con el pigmento negro grafito que, entre otras formas, incluye cajetes, jarras y cántaros con diseños de líneas paralelas, rizos, moños e imágenes serpenteantes.

En el caso de la mayólica, en general tenemos muy bien representados los platos, como lo podemos constatar con los tipos Ciudad de México Azul sobre Crema y Verde sobre Crema, con sus típicas decoraciones vegetales -hojas y palmas- en el borde y en el fondo de las vasijas; el Ciudad de México Blanco, con sus dos variantes y una que se determinó llamar «sucia», por el acabado aparente de un barniz grisáceo de adherencia no uniforme; otra loza blanca que se pudo identificar, aunque escasa, fue el tipo Romita Liso, además de la vajilla blanca con pigmento decorativo azul representada por los tipos San Luis Azul sobre Blanco, con dos líneas paralelas en tono claro por todo el diámetro de la pieza y con otros diseños encimados de posible índole fitomorfa y que fueron trazados con un tono aún más oscuro; el Puebla Azul sobre Blanco presenta decoraciones que incluyen un banda ondulada en color azul claro sobre el cuerpo de las vasijas y, en otros casos, aparecen motivos de apariencia fitomorfa; finalmente, el tipo Santo Domingo Azul sobre Blanco se decora con diseños incompletos. Las tradiciones decoradas con motivos polícromos comprenden 
el Tacuba Polícromo, con motivos de hojas verticales y paralelas dibujadas en tono azul fuerte; la Traza Policromo, con sus peculiares colores amarillo y naranja junto con tonos azules y que se usaron en este caso para esbozar lo que parecen ser diseños florales en las caras internas de las vasijas; por último, el San Juan Polícromo se presenta con un bello ejemplo de un ave pintada en tres colores en el fondo de uno de los recipientes: en azul se delineó la mayor parte del cuerpo, el pico, las patas y las alas se pintaron en amarillo y la espalda en un tono verdoso (Figura 8). A esta lista se pueden agregar los fragmentos de macetas con la superficie cubierta con un esmalte blanco semigrueso sobre el cual se pintaron en verde, con acabados de color amarillento, vegetales muy profusos pero no delicados como en el caso de la mayólica de cocina y de los azulejos de los que se hablará más adelante.

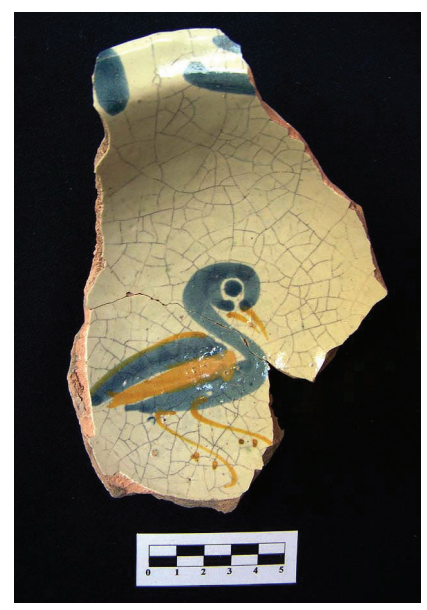

Figura 8: Mayólica mexicana San Juan Polícromo.

La mayólica importada, aunque no es tan abundante como el resto de los fragmentos de manufactura mexicana, sí tiene una importante representación en la muestra del Pozo $\mathrm{n}^{\mathrm{0}} 1$. Los tipos de fabricación ibérica sin decoración que obtuvimos fueron tazones y platos del Columbia Liso, así como platos del llamado Sevilla Blanco, muy escaso en la muestra; de los tipos manufacturados en Italia poseemos un solo fragmento de Liguria Azul sobre Azul, con un diseño original que cubre ambas caras y que parecen ser diseños fitomorfos: plantas con sus ramas en azul claro y las hojas delineadas en azul fuerte. También se identificó la tradición Montelupo Azul sobre Blanco, con líneas muy difuminadas en azul en el labio y en el cuerpo de la pieza. Por otro lado, se rescató un único fragmento de porcelana inglesa con decoración elaborada a partir de la técnica de transferencia, exhibiendo diseños vegetales en dos tonos de azul; finalmente la porcelana china, representada por las tradiciones Kraak y Swatow ${ }^{3}$; de la primera tenemos platos, tazas y tazones decorados con tres tonos de azul, tanto en la cara interna como externa, y se encuentran diseños fitomorfos: flores, hojas, líneas y otras que simulan cabellos ondulados; la segunda tradición está repre-

\footnotetext{
3 Para estudios más específicos sobre la cerámica manufacturada tanto en Asia como en Inglaterra y descubierta en la Ciudad de México pueden verse los trabajos de Patricia Fournier (1990) y George Kuwayana (1997), éste último dedicado únicamente al análisis de la alfarería fabricada en China.
} 
sentada por un plato grande con la rugosidad arenosa en la base que caracteriza a este tipo, decorada el fondo de la pieza con un motivo floral encerrado por tres círculos, mientras que en el cuerpo se aprecian otros dibujos de los que no se puede reconstruir la totalidad del diseño (Figura 9).

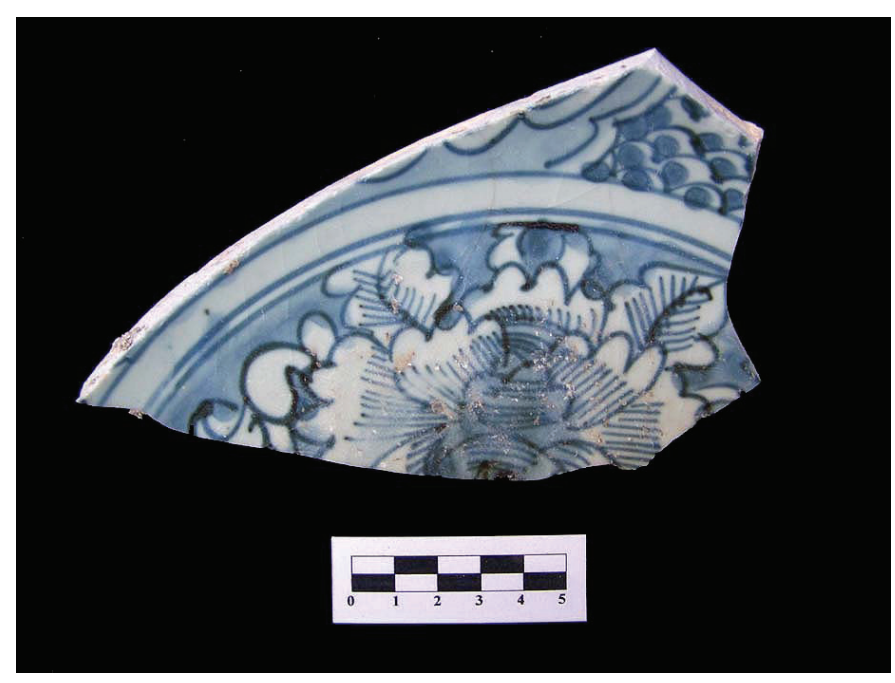

Figura 9: Porcelana china azul Swatow.

\section{Acerca de los azulejos recuperados}

Cuando se efectuaban la labores de excavación en el sector noroeste y a partir del metro de profundidad hasta el 1,70 m de nivel, se halló una buena cantidad de azulejos polícromos, casi completos o en fragmentos, de forma plana o compuestos dos cuadros colocados perpendicularmente por sus bordes- en ángulo recto, que se encontraban originalmente colocados en las orillas de escalinatas o en las esquinas, junto con varios fragmentos de cerámica Ciudad de México Blanco, manteniéndose de igual manera persistente la presencia de alfarería oriental y demás tiestos con engobe pulido; de hecho, en esta área y profundidad es donde más loza de mayólica se había recuperado hasta ese momento. Fueron un total de 13 piezas recuperadas y aunque concuerdan estilísticamente con los estilos decorativos que tenemos en otros ejemplares exhumados en los antiguos restos de la primera catedral, la coloración y los motivos dichos son distintos, por lo que es necesario hacer algunas observaciones al respecto.

Se ha prestado poca atención al estudio de los azulejos en la arqueología colonial mexicana y hay muy pocas publicaciones sobre los mismos. Se han consultado una serie de informes sobre excavaciones en el Centro Histórico que proporcionan valiosa información sobre la presencia de azulejos en los inmuebles; sobresalen sin lugar a dudas los ejemplares rescatados durante las excavaciones arqueológicas tanto en el que fue convento de Santa Teresa la Antigua como también en el inmediatamente 
adyacente predio de la calle de Licenciado Primo Verdad No. 2, donde se ubicaba la antigua casa del siglo XVI que pertenecía a don Juan Luis de Rivera y en donde actualmente se puede apreciar el antiguo Palacio de Odontología de la UNAM. Raúl Barrera (2002) realizó un estudio estilístico de los azulejos recuperados en Santa Teresa y Licenciado Verdad No. 2, pero ninguno de los ejemplares concuerda exactamente con los motivos de los azulejos hallados en la jardinera exterior de la Catedral. Es interesante el artículo de Rosa Guadalupe de la Peña sobre los azulejos adosados a los altares de la primitiva catedral, primero, por la cercanía del antiguo templo con el área del Pozo $\mathrm{n}^{\mathrm{o}} 1 \mathrm{y}$ segundo, por la correspondencia histórica que existe entre un grupo arquitectónico y el otro. En nuestro caso no existe evidencia alguna de azulejos del tipo rehilete ni tampoco de los de diseños antropomorfos o zoomorfos, pero sí pueden enmarcarse dentro de los llamados fitomorfos, aunque con algunas disimilitudes estilísticas. Los colores usados son el azul en al menos tres variantes tonales, el amarillo, el blanco, que sirve de base y mezclas que producen gamas anaranjadas rojizas y verdosas. El azul fue el que más profusamente se ha utilizado para dibujar los vegetales incluyendo las hojas, las flores y las ramas, así como también para delinear los contornos de otros diseños de la misma temática fitomorfa o para la composición de los marcos o paneles que encierran motivos centrales y que fueron hechos con líneas semicurvas o quebradas en ángulo recto (Figura 10); tenemos tambien curvas entrelazadas trazadas con el mismo color, mientras que tanto el amarillo como el anaranjado sirvieron como relleno de hojas y flores, utilizándose el verde solamente en uno de los ángulos de un azulejo compuesto.

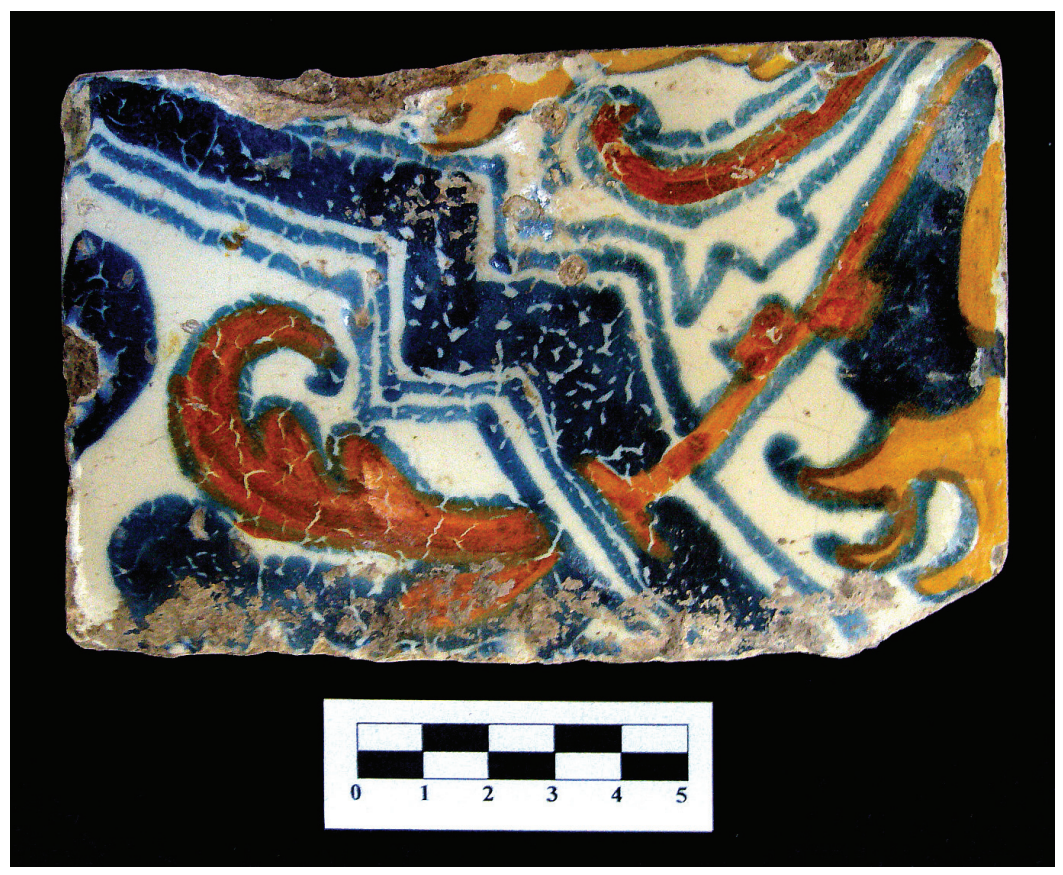

Figura 10: Azulejo polícromo de clara influencia italiana. 
Según la información proporcionada por De La Peña, basada en la comunicación personal del doctor John Hoag, los azulejos de la primera catedral son renacentistas y de tipo islámico (De La Peña 1988: 438); sin embargo se puede añadir alguna información más, ya que al consultar bibliografía sobre el tema y más específicamente el texto de Antonio Sancho Corbacho acerca de los azulejos sevillanos del siglo XVI, es indudable la correspondencia estilística de los ejemplares de la Nueva España con los del Viejo Mundo, y esto se aplica tanto a los azulejos reportados por De La Peña como a los del Pozo $n^{\circ} 1$ del biofiltro. De acuerdo con el autor, las piezas de su estudio proceden de unos cuantos edificios tanto religiosos como civiles, destacando los del convento de Santa Clara por su estado de conservación y su importancia como monumento cerámico, conociéndoseles por la técnica a la italiana o de superficie plana y con la denominación de pisano por ser este el sobrenombre de Francisco Niculoso, un alfarero italiano que fue el introductor de dicha técnica en Sevilla alrededor del año de 1527, aunque como señala Sancho, la producción de azulejos planos en esa región española entre 1530 y 1560 fue muy escasa y no fue hasta el último cuarto del siglo XVI cuando se empezaron a utilizar profusamente en arquitectura (Sancho 1948: 5 , 6 y 8). Esta información cronológica es coherente con el testimonio de Enrique Cervantes acerca de los azulejos que originalmente decoraron la primera Catedral Metropolitana, señalando que la fabricación inicial de dichos productos se llevó a cabo en Puebla a partir de los años 1560 a 1580, siendo ya muy conocida la manufactura poblana en 1602, y supone que en la Ciudad de México se fabricaban igualmente aunque no lo llega a asegurar (Cervantes 1939: 15). Ahora bien, no se tienen los elementos suficientes para determinar la procedencia exacta de los ejemplares de la jardinera de catedral y por lo tanto no se descarta que incluso pudiesen ser un artículo de origen europeo; solamente un estudio más especializado podría determinar la localización del taller de fabricación de las piezas estudiadas.

\section{Restos faunísticos}

Después de los materiales cerámicos, los restos óseos es el segundo grupo más numeroso de evidencias recuperadas dentro de la unidad de excavación, por encima de los artefactos líticos y los fabricados con vidrio. Casi el 100\% de la evidencia ósea exhumada en el Pozo 1 es de origen animal, con excepción de un fragmento de cráneo humano hallado en el Horizonte «a»; los restos eran abundantes en la matriz de la Capa IV, como es común en varios de los contextos coloniales de la Ciudad de México. La muestra estudiada comprende varios segmentos anatómicos de animales que fueron aprovechados en la alimentación humana y por lo tanto muestran marcas de modificación intencional. Los huesos casi en su totalidad están parcialmente fracturados, pero existen varios más que están sumamente fragmentados como se explicará más adelante.

Se lograron identificar algunas especies animales pero a unas cuantas no se les pudo asignar una precisa clasificación taxonómica por el estado fragmentado de los segmentos óseos; se han podido reconocer las especies Ovis aries (borrego u oveja), Capra hircus (cabra), Sus scrofa (cerdo doméstico), Bos taurus (vaca), Meleagris gallopavo (pavo común) y Gallus domesticus (gallina doméstica). 
Mi interés en los huesos de la fauna recuperada del Pozo $n^{\circ} 1$ se centró básicamente en las marcas existentes tanto a nivel superficial o del periostio como a nivel interno, originadas por actividad humana intencional. Al examinar los restos óseos de los animales se pudo evidenciar que muestran tres rasgos diagnósticos esenciales para distinguir una manipulación antrópica con fines indiscutiblemente alimenticios: 1) fracturas intencionales de los segmentos anatómicos, 2) marcas de corte en la superficie del periostio y, 3) cocción.

Las fracturas se produjeron de dos maneras: por percusión mediante un instrumento que no poseía una orilla afilada, y el corte del hueso mediante una herramienta con borde aguzado; en una buena parte de los casos se pueden observar fracturas de tipo helicoidal con la finalidad primaria de obtener la médula de los canales internos o sencillamente romper en dos o más fragmentos el segmento. Se exhumaron algunas esquirlas de huesos largos y se recuperaron tanto fragmentos de diáfisis como huesos largos sin epífisis, junto con otra serie de otros restos óseos que también habían sufrido una serie de torceduras mediante flexión para desprender algunas partes que no lograban quitarse solamente con percusión. Tenemos tibias de borrego que presentan las diáfisis fracturadas y algunas de ellas con marcas de corte contundente transversal que se efectuaron para partir el hueso; se hallaron también radios de la misma especie y fémures de vaca cortados de la misma manera, mientras que en algunos casos se aprecian claramente hundimientos en la corteza ósea por percusión, provocada mediante un artefacto activo no afilado evidenciado en la metáfisis del fémur de una vaca (Figura 11) y en la diáfisis del metacarpo de un cerdo, ambos con pedazos de hueso que por estar originalmente fresco el segmento no se lograron desprender de la superficie. Existen además mandíbulas de cerdo que fueron desprendidas del cráneo mediante la rotura de sus ramas, efectuada por una serie de cortes contundentes. Por otra parte, las delgadas y sutiles o profundas marcas de corte se presentan en buena cantidad y las podemos encontrar aisladas, pero en la mayoría de los casos en compañía de otras marcas asociadas directamente con la percusión divisoria de huesos; tal es el caso de algunas costillas de vaca (Figura 12) o en el cuello del cóndilo de una escápula de borrego.

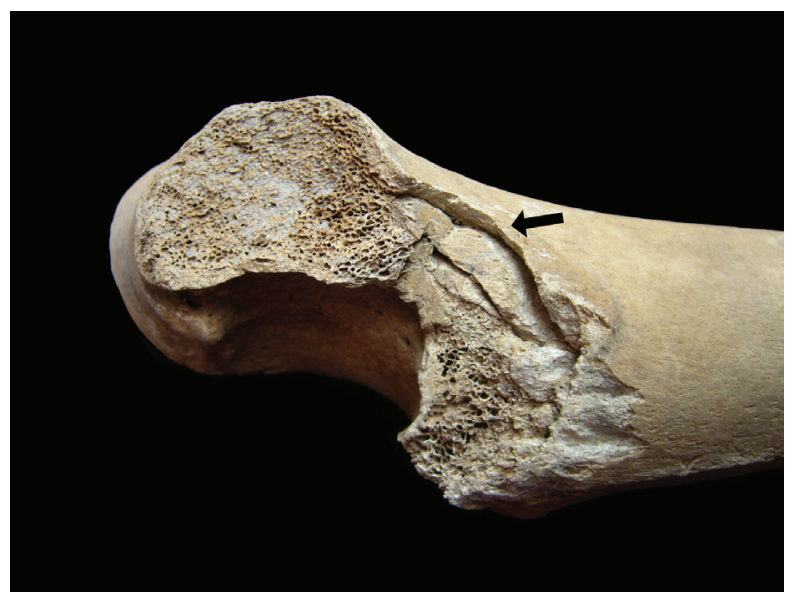

Figura 11: Fémur de bos con hundimiento por impacto. 


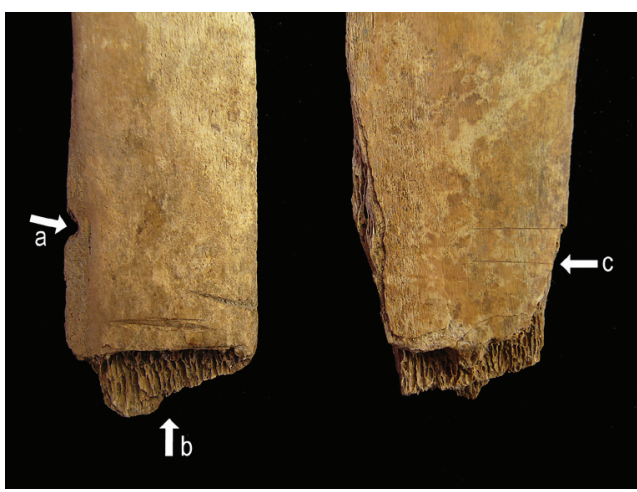

Figura 12: Costillas de bos con marcas de corte.

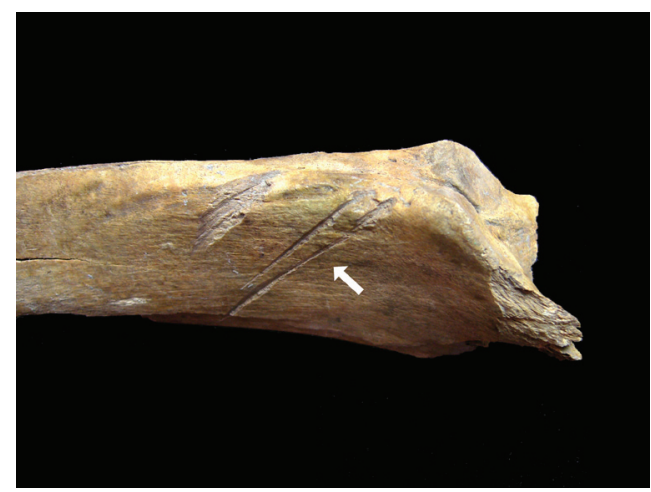

Figura 13: Espina de vértebra de bos con huellas de cortes contundentes.

Las marcas de corte se pueden observar en toda una serie de huesos distintos, como son pelvis de cerdo, en metáfisis de fémures de cerdo, justo en el área de inserción de tejido muscular, en la espina dorsal de vértebras de vaca (Figura 13) y, para el caso de borregos, en diáfisis de radios que también fueron cocidos, en el cuello del cóndilo de una escápula, en la cara lingual y bucal en mandíbulas, así como en metapodiales, en costillas justo en el área fracturada, y en vértebras.

Finalmente, la cocción de los huesos con finalidades alimenticias es un rasgo muy característico de una buena parte de la muestra rescatada y dichos elementos diagnósticos -tonalidades café difuminadas en compañía de una apariencia lustrosa y endurecimiento de la estructura ósea- asociados a esta actividad- se observan en casi todas las especies identificadas; buen ejemplo de ello es una escápula de cerdo, en cuanto a la uniformidad del patrón físico de cocción (Figura 14). Pero existen un par de ejemplares que curiosamente exhiben una pequeña mancha oscura que indica claramente una exposición directa al fuego, como es el caso de un radio de borrego, que además fue cocido, y una astilla grande de hueso largo de vaca.

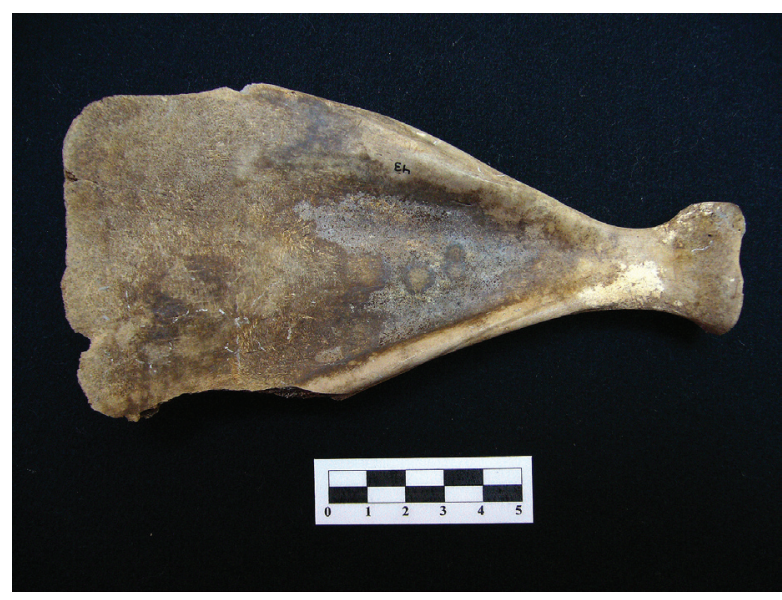

Figura 14: Escápula de sus hervida. 


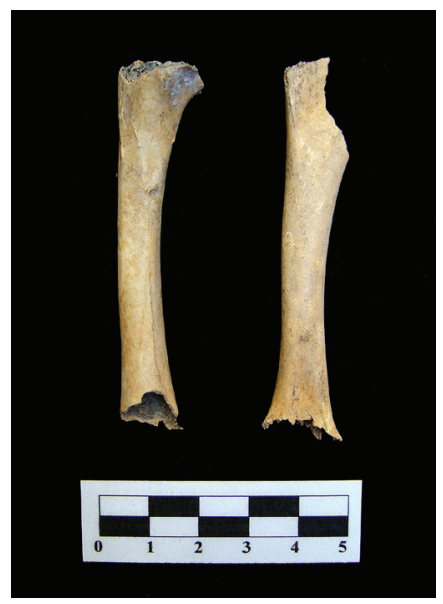

Figura 15: Dos fémures de gallus con ambas epífisis eliminadas.

Con carácter secundario respecto a estos tres procesos antrópicos, tenemos la eliminación de epífisis en huesos largos de animales pequeños, básicamente gallinas, por medio de la mordida y masticación durante el consumo directo, como podemos apreciar en un par de fémures excavados en el Pozo n 1 (Figura 15). Se hallaron además unos cuantos segmentos de hueso que resentan en su superficie zonas manchadas con una tonalidad verdosa que, según los especialistas, fueron provocadas por el contacto directo del material óseo con artefactos de metal que, en el momento de exponerse a la humedad, sufrieron una oxidación dejando esa peculiar marca en el hueso; para el caso, se pueden señalar una escápula de borrego (Figura 16) y un hueso largo de animal no identificado con una pátina verde bastante uniforme a lo largo de su superficie.

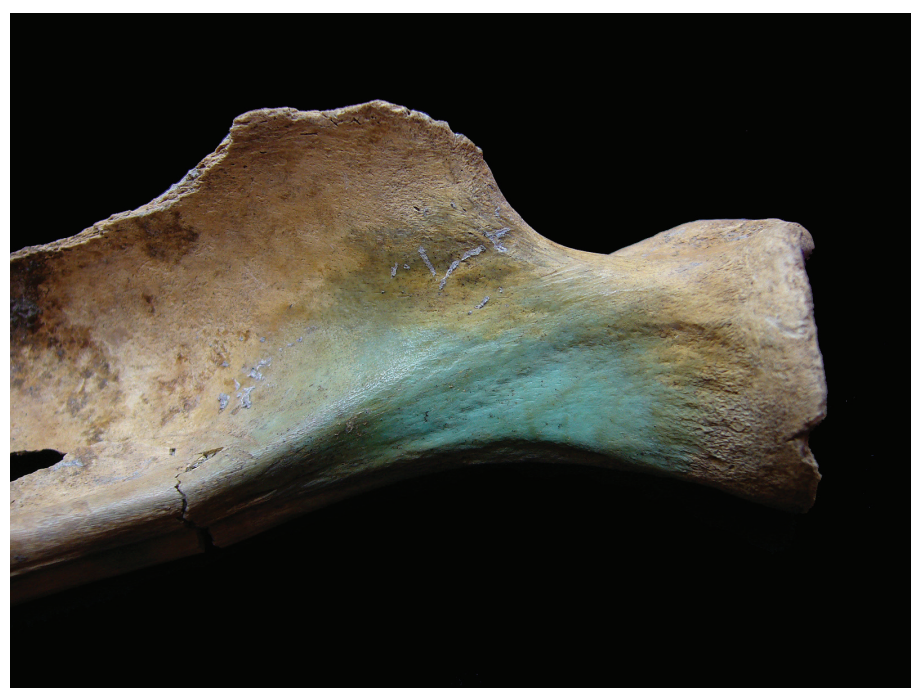

Figura 16: Escápula de ovis exhibiendo una mancha verde producida por oxidación. 


\section{Reflexiones concernientes a la evidencia material hallada en el Pozo $\mathbf{n}^{0} 1$}

La sola idea de poder sondear a pocos metros de donde se encontraba la antigua catedral resultó muy atractiva, y aunque la evidencia arquitectónica y arqueológica en sí no esclarecen mucho la relación de estos restos con la información conocida acerca de la Catedral Metropolitana, sí queda claro que las construcciones exhumadas en el reducido pozo excavado son contemporáneas con la erección de la primera iglesia o antigua catedral, es decir durante el siglo XVI y pocos años de consumada la Conquista. Es probable que dichas ruinas pertenecieran a un conjunto arquitectónico circundante al primer templo católico de la capital de la Nueva España.

Los materiales exhumados en el rescate de la unidad de excavación parecen indicarnos que se trata sin duda de depósitos de lo que al parecer fue la basura acumulada en el sedimento que sirvió para cubrir los restos arquitectónicos explorados, aunque no podemos saber con precisión quién o quiénes fueron los depositarios de los ya inservibles artefactos cerámicos y los restos alimenticios. La calle del Empedradillo es muy recordada en la historia, principalmente por haber estar funcionando en esa zona el antiguo corral y rastro de reses que surtían a los locales establecidos en la Plaza Mayor y a los comercios de comida de la ciudad. El establecimiento del siglo XVI duró más de 20 años, hasta que el Cabildo del $1^{\circ}$ de Marzo de 1543 determinó que los rastreros suspendieran las actividades de matanza de los animales y se mudaran al primer emplazamiento que se encontraba al sur de la ciudad (Trens 1957: 80). De cualquier manera, tanto por la cantidad y calidad de los mismos, como por el área del descubrimiento, podemos suponer que originalmente fueron productos aprovechados por una clase media/alta e incluso yendo más lejos y por la naturaleza de los residuos en relación con los cúmulos de aplanado, los fragmentos de azulejos y lo aparentemente alterado de las construcciones, podría tratarse de evidencia asociada a los trabajadores o albañiles que estuvieron directamente relacionados con la actividad de edificación y relleno tanto del pilar como del basamento. No se descarta que los huesos de los animales fueran consumidos total o parcialmente por los trabajadores y que la loza fragmentada, comúnmente asociada a estratos sociales más altos, fuese aprovechada en la acumulación de sedimento de relleno.

\section{Referencias bibliográficas}

BARRERA RodríGUEz, Raúl

2002 El antiguo Palacio de Odontología de la UNAM a través de su espacio y tiempo arqueológicos. Tesis de licenciatura. México: Escuela Nacional de Antropología e Historia - Instituto Nacional de Antropología e Historia - Secretaría de Educación Pública.

Cervantes, Enrique A.

1939 Loza blanca y azulejo de Puebla. México.

De La PeÑa Vírchez., Rosa Guadalupe

1988 «Azulejos encontrados in situ: primera catedral de México», en Ensayos de alfarería prehispánica e histórica de Mesoamérica, Mari Carmen Serra y Carlos Na- 
varrete, eds., pp. 417-440. México: Instituto de Investigaciones Antropológicas, Universidad Nacional Autónoma de México.

Fournier García, Patricia

1990 Evidencias arqueológicas de la importación de cerámica en México, con base en los materiales del ex-convento de San Jerónimo. México: Instituto Nacional de Antropología e Historia.

GoGGIN, John M.

1968 Spanish Majolica in the New World. Types of the Sixteenth to Eighteenth Centuries. New Haven: Yale University Publications in Anthropology.

1970 «The Spanish Olive Jar», en Papers in Caribbean Anthropology, Sidney W. Mintz, ed., pp. 1-48. New Haven: Human Relations Area Files Press.

GonzÁlez Rul, Francisco

1988 La cerámica de Tlatelolco. México: Instituto Nacional de Antropología e Historia.

KuWAYANA, George

1997 Chinese Ceramics in Colonial Mexico. Honolulu: University of Hawaii Press.

Lister, Florence C. y Robert H. Lister

1982 Sixteenth Century Maiolica Pottery in the Valley of México. Tucson: The University of Arizona.

LóPez CERVANTes, Gonzalo

1976 Cerámica colonial en la Ciudad de México. México: Instituto Nacional de Antropología e Historia.

1982 «Informe preliminar sobre los materiales coloniales», en El Templo Mayor: excavaciones y estudios, Eduardo Matos Moctezuma, coord., pp. 255-282. México: Instituto Nacional de Antropología e Historia.

Nebot García, Edgar

2009 Informe final del rescate arqueológico «Biofiltro Catedral» efectuado entre la calle de Monte de Piedad y Plaza de la Constitución, en el Centro Histórico de la Ciudad de México: excavaciones y análisis de material. México: Informe firmado en coautoría con Raúl Barrera Rodríguez y suministrado al Archivo Técnico de la Coordinación Nacional de Arqueología del INAH, Programa de Arqueología Urbana/Museo de Templo Mayor, Instituto Nacional de Antropología e Historia.

Noguera, Eduardo

1975 La cerámica arqueológica de Mesoamérica. México: Instituto de Investigaciones Históricas, Universidad Nacional Autónoma de México.

Sancho Corbacho, Antonio

1948 La cerámica andaluza. Azulejos sevillanos del siglo XVI. Madrid/Sevilla: Laboratorio de Arte, Universidad de Sevilla.

Toussaint, Manuel

1992 La Catedral de México y el Sagrario Metropolitano. México: Editorial Porrúa.

Trens, Manuel B.

1957 México de antaño. México: Talleres Gráficos de la Nación.

Vega Sosa, Constanza

1975 Forma y decoración en las vasijas de tradición azteca. México: Instituto Nacional de Antropología e Historia. 